\title{
Mechanical ventilation and volutrauma: study in vivo of a healthy pig model
}

\author{
Camilla V Pastore', Federica Pirrone', Silvia Mazzola ${ }^{1}$, Manuela Rizzi², Manuela Viola², Giuseppe Sironi ${ }^{3}$, \\ Mariangela Albertini ${ }^{1}$
}

${ }^{1}$ Department of Animal Pathology, Hygiene and Public Veterinary Health, Section of Biochemistry and Physiology, University of Milan, Italy; ${ }^{2}$ Department of Experimental and Clinical Biomedical Sciences, University of Insubria, Italy; ${ }^{3}$ Department of Animal Pathology, Hygiene and Public Veterinary Health, Section of Veterinary Pathological Anatomy and Avian Pathology, University of Milan, Italy.

\begin{abstract}
Mechanical ventilation is essential in intensive care units. However, it may itself induce lung injury. Current studies are based on rodents, using exceptionally large tidal volumes for very short periods, often after a "priming" pulmonary insult. Our study deepens a clinically relevant large animal model, closely resembling human physiology and the ventilator setting used in clinic settings. Our aim was to evaluate the pathophysiological mechanisms involved in alveolo/ capillary barrier damage due to mechanical stress in healthy subjects. We randomly divided 18 pigs (sedated with medetomidine/tiletamine-zolazepam and anesthetised with thiopental sodium) into three groups $(n=6)$ : two were mechanically ventilated (tidal volume of 8 or $20 \mathrm{ml} / \mathrm{kg}$ ), the third breathed spontaneously for 4 hours, then animals were sacrificed (thiopental overdose).

We analyzed every $30^{\prime}$ hemogasanalysis and the main circulatory and respiratory parameters. Matrix gelatinase expression was evaluated on bronchoalveolar lavage fluid after surgery and before euthanasia. On autoptic samples we performed zymographic analysis of lung, kidney and liver tissues and histological examination of lung.

Results evidenced that high $\mathrm{V}_{\mathrm{T}}$ evoked profound alterations of lung mechanics and structure, although low $\mathrm{V}_{\mathrm{T}}$ strategy was not devoid of side effects, too. Unexpectedly, also animals that were spontaneously breathing showed a worsening of the respiratory functions.
\end{abstract}

Key terms: gelatinases, mechanical ventilation, pig, ventilator induced lung injury (VILI).

\section{INTRODUCTION}

Mechanical ventilation is essential to sustain ventilatory function in patients with respiratory failure and during general anaesthesia. However, this is a potentially harmful therapeutic intervention, since it can initiate lung injury also in healthy lungs (Dreyfuss and Saumon, 1998; ARDS network 2000). Despite the life-saving potential of this assistance, several drawbacks and complications have been identified early in the use of mechanical ventilation, so the concept of ventilatorinduced lung injury (VILI) was introduced (Pingleton, 1988). VILI has recently received much attention in both experimental and clinical fields (Amato et al., 1998), and many studies have been performed to evaluate the effects of sustained elevation in lung volume (Ricard et al., 2003). The underlying molecular mechanisms of VILI have not been fully elucidated, but the histological appearance of the lung tissue is similar to acute lung injury/acute respiratory distress syndrome (ALI/ARDS) (Nakos et al., 2006). Clinical studies demonstrate that if the use of large tidal volumes $\left(\mathrm{V}_{\mathrm{T}} \geq 10-12 \mathrm{ml} / \mathrm{kg}\right)$ is associated with a poor prognosis, also a "lung-protective" ventilation strategy $\left(\mathrm{V}_{\mathrm{T}} \leq 10-12 \mathrm{ml} / \mathrm{kg}\right)$, associated with a suitable positive endexpiratory pressure, reduces but does not prevent the onset of VILI (Vaneker et al., 2007). To further improve the outcome of critically ill patients, a better understanding of the detrimental mechanisms of VILI is therefore required.

The cytopathological changes of the lungs caused by overdistension are characterized by loss of blood gas barrier integrity and namely haemorrhage, edema and inflammatory cells influx (Ricard et al., 2003). Edema formation in alveolar spaces causes profound changes in pulmonary mechanics and gas exchange, that may be important limitingperformance factors, especially when correlated with hypoxia (Wirtz and Dobbs, 2000). The development of interstitial pulmonary edema has been associated with the degradation of the proteoglycans and a weakening of intramolecular bonds between fibres, causing a disorganization of the threedimensional extracellular matrix (ECM) fibre mesh and an increase of the amount of water that can be accommodated in the tissue (Dreyfuss et al., 1985). In this process various proteolytic enzymes are involved, including metalloproteinases (MMPs), holding a major role. MMPs are a family of zincdependent endopeptidases that can cleave virtually all components of the extracellular matrix, and currently are viewed also as modulators of cell-cell and cell-matrix interactions (Albaiceta et al., 2008). Expression of MMPs in the lung is modulated by a wide range of factors, including the mechanical stimuli that continuously change airway pressure as part of the dynamic breathing cycle (Greenlee et al., 2007). Particularly, the gelatinases are secreted as latent forms by a variety of cell types and they are activated in extracellular spaces by serine proteases and other MMP members (Woessner, 1991; Tomashefski, 1990). MMP-2 (gelatinase A, $72 \mathrm{kDa}$ ) and MMP-9 (gelatinase B, $92 \mathrm{kDa}$ ) have the capacity to degrade gelatine, elastin, fibronectin and type IV collagen, which are the major structural components of the basement membrane (Woessner, 1991). MMP-9 is stored in neutrophils granules and rapidly released after cellular activation. MMP-9 has been 
implicated in extracellular matrix remodelling and in cell migration during acute inflammation, and, since it has been found to be raised in patient with ALI, it has been investigated in lung injury research protocols (Albaiceta et al., 2008).

MMP-2 is the most widely distributed MMP and is constitutively expressed by various cell types, including endothelial and epithelial cells. Under physiological conditions, small amounts of MMP-2 are present in the lining fluid of the lung, while MMP-9 is upregulated under many pathological conditions.

Current studies on VILI are mainly based on rodents, models that do not allow the proper measurements of the changes in respiratory mechanics, pulmonary arterial pressure, gas exchanges evolution and alveolo-capillary barrier permeability, consequent to MV. In addition, rodents are often ventilated with high tidal volumes for a very short period of time, mainly after a "priming" pulmonary insult. Our large animals model, based on healthy pigs, has the peculiarity of being clinically relevant, since it is well know that swine physiology is very close to that of the human race, and the ventilator setting that we adopted is compatible with those currently used in the clinical arena.

This study allowed us to evaluate continuously, during mechanical stress, the pathophysiological changes in alveolocapillary barrier functionality and the most important cardio respiratory parameters that are an irreplaceable presence in intensive care units. Moreover, in the ex vivo part of the study, the gelatinase zymography and the histological analysis performed gave us the opportunity to compare and eventually confirm the "bedside data", obtained in the four hours of the in vivo part of the study.

\section{METHODS}

Animals

The study was performed using 18 Large White pigs (Sus domesticus) of either sex (Istituto Zooprofilattico della Lombardia e dell'Emilia, Brescia, Italy), weighing $22.07 \pm 2.51 \mathrm{~kg}$ (mean \pm SD), fed with a standard diet with free access to water, and deprived of food for $12 \mathrm{~h}$ before experimentation. Animal care and treatment were conducted in accordance with institutional guidelines in compliance with national (D.L. n.116 G.U., suppl.40, 18/02/1992; Circolare n.8, G.U., 14/07/1994) and international (EEC Council Directive 86/609, OJL358-1, December 1987; Guide for the Care and Use of Laboratory Animals, U.S., National Research Council, 1996) laws and policies.

\section{Experimental protocol and procedures}

Pigs were sedated with medetomidine $(0.03 \mathrm{ml} / \mathrm{kg}$ i.m., Pfizer Italy s.r.1.) and tiletamine-zolazepam $(4 \mathrm{mg} / \mathrm{kg}$ i.m., Virbac S.r.l., Italy), and anesthetised with $15 \mathrm{mg} / \mathrm{kg}$ of thiopental sodium (Farmitalia Carlo Erba, Milan, Italy) injected into the auricular vein. A steady depth of anesthesia was maintained during the experimental protocol by continuous infusion of dilute solution of thiopental sodium $(9 \mathrm{mg} / \mathrm{kg} / \mathrm{h})$. Animals were tracheostomized, intubated, and randomly divided into three groups.

The first group ( $n=6$; tidal volume of $8 \mathrm{ml} / \mathrm{kg}-\mathrm{V}_{\mathrm{T}} 8$ ) and the second group ( $n=6$; tidal volume of $20 \mathrm{ml} / \mathrm{kg}$ $\mathrm{V}_{\mathrm{T}}$ 20) were mechanically ventilated using a $900 \mathrm{C}$ Servo ventilator (Siemens-Elema, Sweden) for $240 \mathrm{~min}$. The third group $(n=6)$ was used to test the animal response to the experimental procedures and studied for the same period in spontaneous breathing (SB). Ventilator settings consisted of a fixed tidal volume of $8 \mathrm{ml} / \mathrm{kg}$ or $20 \mathrm{ml} / \mathrm{kg}$, which was started immediately after intubation. The ratio of inspiratory to total breathing cycle duration was $0.33 \pm 0.01$. A positive end-expiratory pressure (PEEP) of $4 \mathrm{cmH}_{2} \mathrm{O}$ was selected for the two mechanically ventilated groups. To reduce the effects of the compliance of the system connecting the animal to the ventilator on the mechanics measurements, a fixed-length standard low-compliance tube was used (2 $\mathrm{cm}$ internal diameter, $60 \mathrm{~cm}$ long) and the humidifier was omitted from the inspiratory line. The equipment dead space was $29.5 \mathrm{ml}$. The tracheal cannula was connected to a Fleisch pneumotachograph no.2 (Fleisch, Lausanne, Switzerland) to record the respiratory airflow and, by integration, the tidal volume. The pressure drop across the two ports of the pneumotachograph was measured with a differential pressure transducer (Statham PM 15, 10846). The static compliance of the respiratory system (Crs) was obtained as described previously (Clement et al., 1998). Polyethylene catheters were inserted into the right femoral artery to monitor the systemic arterial pressure and into the right femoral vein for drug and fluid (normal saline) administration. A fluid strategy to adequately compensate fluid loss and to keep the animals haemodynamically stable were adopted.

A balloon-tipped catheter (Pediatric Swan-Ganz 5F) was introduced into the pulmonary artery to measure pulmonary arterial pressure. Systemic and pulmonary arterial pressures were recorded by connecting the catheters to a fluid-filled capacitance manometer (4-422 Bell and Howell). All signals were calibrate independently and recorded simultaneously on a six-channel pen recorder (Nec San-ei Instruments Polygraph mod. 8K40, Ltd).

PiCCO catheters (PiCCO device, Pulsion Medical System, Munich, Germany) were inserted into the left jugular vein and into the left femoral artery for extravascular lung water (EVLW), extravascular lung water index (EVLWi), pulmonary blood volume (PBV) and cardiac index (CI) evaluation.

All the hemodynamic and respiratory parameters were continuously monitored and registered at baseline and every $30 \mathrm{~min}$ until the end of the experiment.

At the end of the experimental time, all the animals were sacrificed with a thiopental overdose, and lung, liver and kidney tissue samples were harvested and fixed in $10 \%$ formalin or immediately frozen in liquid nitrogen and keep at $-80^{\circ} \mathrm{C}$ until use.

\section{Hemogasanalysis}

Arterial blood samples were collected in heparin (Parke-Davis, Milan, Italy) every $30 \mathrm{~min}$ and hemogasanalysis $\left(\mathrm{PaCO}_{2}\right.$ and $\mathrm{PaO}_{2}$ ), $\mathrm{pH}$ and hematocrit were immediately evaluated (IL 1640, Instrumentation Laboratory System).

\section{Bronchoalveolar lavage fluid analysis}

Bronchoalveolar lavage fluid (BALF) was performed after surgical procedure and at the end of the experiment, with saline $\left(30 \mathrm{ml}\right.$ heated to $\left.37^{\circ} \mathrm{C}\right)$ injected and re-aspirate by a polyethylene catheter inserted into the tracheal cannula 
and advanced into a segmental bronchus. BAL fluid was centrifuged $\left(1200 \mathrm{~g}\right.$ for $10 \mathrm{~min}$ at $\left.4^{\circ} \mathrm{C}\right)$ and the recovered supernatant was frozen and stored at $-20^{\circ} \mathrm{C}$ until further processing. The quantification of MMP-2 and MMP-9 in BALF was done by using the ELISA kit Matrix Metalloproteinase-2 and Matrix Metalloproteinase-9 Biotrack Activity Assay System (Amersham Biosciences, Little Chalfont, UK) following the manufacturer's instruction. To determine total MMPs activity (i.e., pro- plus active MMPs), samples were treated with $p$-aminophenylmercuric acetate (APMA) and then tested with the ELISA kit reported above.

\section{Zymography}

Frozen lung, liver and kidney tissue samples were used to detect MMP-2 and MMP-9 activities by zymography, as previously described (Vigetti et al., 2006). Briefly, tissues were homogenized in $10 \mathrm{mM}$ Tris- $\mathrm{HCl}, 150 \mathrm{mM} \mathrm{NaCl}, 20 \mathrm{mM}$ EDTA, $\mathrm{pH} 7.5$ and the protein content was assessed by the Bradford method. The same amount in protein of each extract $(5 \mu \mathrm{g})$ was loaded on a SDS polyacrylamide gels containing $1 \mathrm{mg} /$ $\mathrm{ml}$ gelatine and the samples were run at $150 \mathrm{~V}$ for 1 hour in a minigel apparatus. The samples were loaded in the gels without heat denaturation and reducing agents. After the run, the gels were washed at room temperature for $2 \mathrm{~h}$ in $2.5 \%$ Triton X-100 and incubated overnight at $37^{\circ} \mathrm{C}$ in $10 \mathrm{mM} \mathrm{CaCl}_{2^{\prime}}$ $150 \mathrm{mM} \mathrm{NaCl}$, and $50 \mathrm{mM}$ Tris-HCl, pH 7.5 buffer. The gel was stained in $2 \%(\mathrm{v} / \mathrm{v})$ Coomassie Blue G-250 in fixing solution and photographed on a light box after appropriate destaining. Proteolysis was detected as white bands in a dark blue field and evaluated using an imaging densitometer (model GS700, BioRad Lboratories, Hercoles, CA) and the band density was measured by ImageJ software (National Institutes of Health, Bethesda, MD).

\section{Histological Analysis}

Lung tissue samples fixed in $10 \%$ buffered formalin were used for histological analysis. Lung sections $(4 \mathrm{~mm})$ were stained with hematoxylin-eosin and analysed by a pathologist who was blinded to group identity. To identify VILI a quantitative scale scoring alveolar emphysema, interstitial emphysema, atelectasia and inflammation response (scored from 0 to 4 each) was used according to the following scheme: 0 - no lesions, 1 - mild, focal lesions, 2 - mild, diffuse lesions, 3 - moderate lesions, 4 - severe lesions. The presence of bronchospasm was also evaluated and scored as: 0 - no lesions, $\mathrm{F}$ - focal, $\mathrm{W}-$ widespread.

\section{Statistical Analysis}

Data are presented as means $\pm \mathrm{SD}$. The statistical significance of difference between or within the groups for all parameters was evaluated by ANOVA for repeated measures. Multiple comparisons were performed using a post hoc Tukey test (SPSS Version 15.0, Inc., Chicago, IL, USA). Differences are considered significant at $p<0.05$.

\section{RESULTS}

In figure 1 is reported the mean pulmonary arterial blood pressure in all experimental groups. Animals of the SB group showed a significant increase of MPAP between 120 and 180 min both in comparison with the others two groups and with time 0 min.

In figure 2 are described the changes in EVLWi (fig. 2a) and in the EVLW/PBV ratio (fig. 2b). In the SB group, EVLWi, which represents a precise but non-specific index of presence of interstitial fluid in the lung, was significantly increased after $240 \mathrm{~min}$, evidencing edema formation. (fig. 2a). This parameter at 240 min was significantly higher in $\mathrm{SB}$ group than in $\mathrm{V}_{\mathrm{T}} 8$ and $\mathrm{V}_{\mathrm{T}} 20$ groups. The EVLW/PBV ratio (fig. $2 b$ ) is an accurate index of pulmonary capillary district permeability. At $240 \mathrm{~min}$, this value was significantly higher in the $\mathrm{V}_{\mathrm{T}} 20$ group than the 0 time and than in the other two groups.

In figure 3 , the changes in the respiratory system compliance $(\mathrm{Crs})$ are shown. Comparing time 0 to $240 \mathrm{~min}$, the values were not significantly different in all groups. The analysis among groups showed that at time $0 \mathrm{Crs}$ value was significantly higher in the $\mathrm{V}_{\mathrm{T}} 20$ group than in the other two groups, and at $240 \mathrm{~min} C \mathrm{Cr}$ value was significantly lower in SB group than in the $\mathrm{V}_{\mathrm{T}} 8$ and $\mathrm{V}_{\mathrm{T}} 20$ groups.

The tidal volume in spontaneously breathing group reached a value of $6.3 \pm 1.8 \mathrm{ml} / \mathrm{kg}$ at time $0 \mathrm{~min}$ and of $7.2 \pm$ $1.7 \mathrm{ml} / \mathrm{kg}$ at time $240 \mathrm{~min}$. The difference between time $0 \mathrm{~min}$ and time $240 \mathrm{~min}$ was statistically significant $(p<0.05)$ (data not reported).

Figure 4 evidences the changes in $\mathrm{PaO}_{2}$ (fig. 4a) and in $\mathrm{PaCO}_{2}$ (fig. 4b). As expected, in animals ventilated with high volumes, oxygenation levels were higher than in the other two groups. This difference becomes significant at $30 \mathrm{~min}$ and between 90 and $240 \mathrm{~min}$, reaching $\mathrm{PaO}_{2}$ values of about 120 mmHg. In all the observation times $\mathrm{PaCO}_{2}$ was significantly higher in the $\mathrm{V}_{\mathrm{T}} 8$ group than in the $\mathrm{SB}$ and $\mathrm{V}_{\mathrm{T}} 20$ groups, reaching severe hypercapnic levels. In the SB group $\mathrm{PaCO}_{2}$ values remained within the physiological range and the $\mathrm{V}_{\mathrm{T}} 20$ group was hypocapnic. As a consequence, at the end of the experiments, $\mathrm{pH}$ levels reached a value of $7.4 \pm 0.009$ in spontaneously breathing pigs, of $7.20 \pm 0.15$ in $\mathrm{V}_{\mathrm{T}} 8$ group and of $7.6 \pm 0.03$ in $\mathrm{V}_{\mathrm{T}} 20$ group. The levels in $\mathrm{V}_{\mathrm{T}} 20$ group were significantly higher than in the other two groups $(p<0.001)$.

Figure 5 shows the changes in cardiac output (CO). The SB group showed significantly higher values than the $V_{T} 8$ and $\mathrm{V}_{\mathrm{T}} 20$ groups, both at time $0 \mathrm{~min}$ and at time $240 \mathrm{~min}$.

The mean systemic arterial blood pressure and the heart rate remained stable in all animals for the duration of the experiment, with no relevant difference among the groups (data not reported).

MMP-2 and MMP-9 levels were analyzed as zymogen and as active form in lung, kidney and liver autoptic samples by zymography. In the lung, both forms of MMP-2 (fig. 6a) were detected in all the animals, and the level of activated MMP-2 was significantly higher in all groups than the inactive form. Therefore, analyzing the differences among groups, the activated MMP-2 was significantly higher in $\mathrm{V}_{\mathrm{T}} 20$ group than in the other two groups. In the kidney, the inactive form of MMP-2 (fig. 6b) was significantly higher in the spontaneously breathing group than in the $\mathrm{V}_{\mathrm{T}} 8$ and $\mathrm{V}_{\mathrm{T}} 20$ groups, and it was significantly higher than the MMP- 2 in the $\mathrm{SB}$ and $\mathrm{V}_{\mathrm{T}} 8$ groups. The MMP-2 activation was specular: indeed, the active form was mainly expressed in the $\mathrm{V}_{\mathrm{T}} 20$ group, in which it reached significantly higher levels than in the other two groups and than the inactivated form. In the liver, the proMMP-2 (fig. 6c) was synthesized in all the animals, but it was significantly 
lower in the $\mathrm{V}_{\mathrm{T}} 20$ group than in the other two groups. Similarly, the MMP-2 activated form was significantly lower in the $\mathrm{V}_{\mathrm{T}} 20$ group than the $\mathrm{SB}$ and $\mathrm{V}_{\mathrm{T}} 8$ groups. In all groups, the proMMP-2 was significantly higher than the activated form.

The active form of MMP-9 was never observed in all groups and in all samples. In the lung (fig. 7a), the inactive form of MMP-9 was present in all the animals, but in the $\mathrm{V}_{\mathrm{T}} 20$ group the expression was significantly higher than in the other two groups. In the kidney (fig. 7b) and in the liver (fig. 7c), the inactive form of the MMP-9 was synthesized in all subjects without any significant difference among groups.

Data of gelatinases in BALF, evaluated with ELISA analysis, are presented in Figure 8 (MMP-2 8a; MMP-9 8b). At time 0 min, MMP-2 was detectable, in both forms in all groups without significant differences. At the end of the experiment, MMP-2 was synthesized and activated in all the subjects, but in $\mathrm{V}_{\mathrm{T}} 8$, the MMP-2 activated form was significantly higher than in the other two groups. In the $\mathrm{SB}$ and $\mathrm{V}_{\mathrm{T}} 20$ groups, the proMMP-2 was significantly higher at time $240 \mathrm{~min}$ than at time 0 min (fig.8a). At time 0 min, MMP-9 was detectable in all groups in both forms without significant differences, while at $240 \mathrm{~min}$ activated MMP-9 in the $\mathrm{V}_{\mathrm{T}} 8$ group reached significantly higher values in comparison to the $\mathrm{SB}$ and $\mathrm{V}_{\mathrm{T}} 20$ groups. (fig. 8b).

The results of histological analysis are briefly summarized in table 1. In the SB group samples, modest alterations related to acute alveolar emphysema, interstitial emphysema, atelectasia and inflammation (score 1) were noted. In the specimens of the $\mathrm{V}_{\mathrm{T}} 8$ group, minor acute alveolar emphysema injuries, interstitial emphysema and atelectasia (score 1) were present, associated with focal bronchoconstriction. In the sections analyzed, inflammation (moderate, score 2), with granulocyte marginalization and diapedesis, alveolar macrophages desquamation and moderate fibrin deposition were found. In $\mathrm{V}_{\mathrm{T}} 20$ subjects, the acute alveolar emphysema lesions were diffuse, with widespread alveolar septa breaking (score 4). Moderate interstitial emphysema (score 1) was pointed out. Bronchospasm (score W) was evident in numerous sections of bronchi and bronchioles, atelectasia (score 2) and inflammatory processes (score 3) were also observed, with haemorrhagic diathesis and neutrophilic diapedesis.

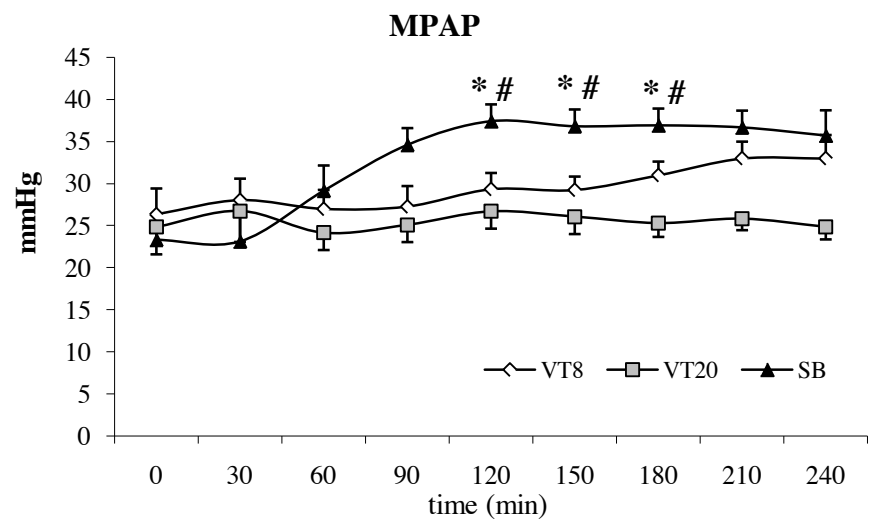

Figure 1. Pulmonary arterial blood pressure (MPAP). Time course of MPAP changes in all experimental groups $(n=6)$. The values are expressed as means $\pm \mathrm{SD}$. $p<0.05$ vs $\mathrm{V}_{\mathrm{T}} 8$ and $\mathrm{V}_{\mathrm{T}} 20$ groups; \# $p<0.05$ vs time $0 \mathrm{~min}$.
EVLWi

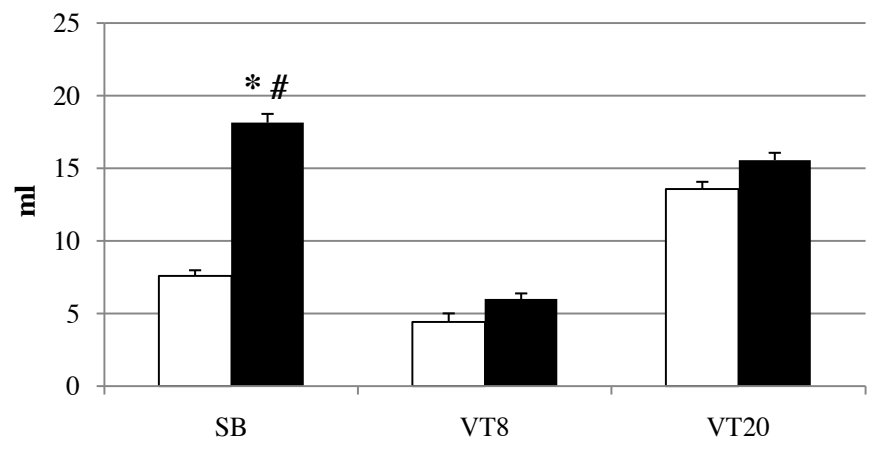

EVLW/PBV

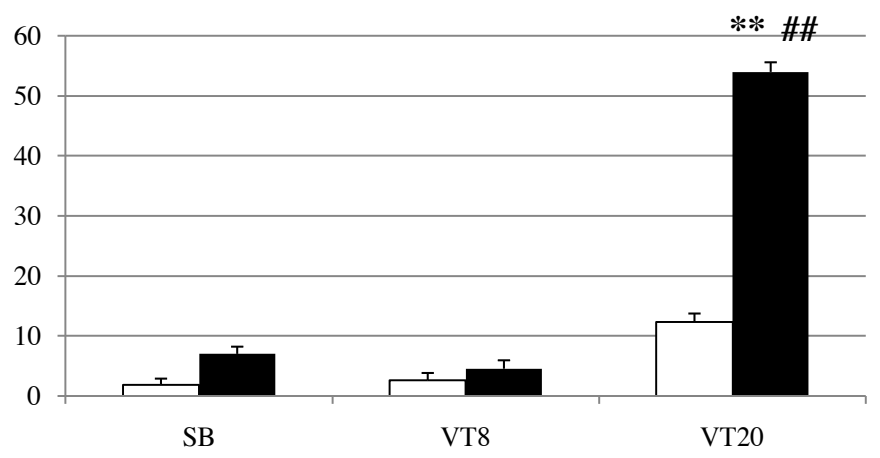

Figure 2. Extravascular lung water index (EVLWi) and extravascular lung water/pulmonary blood volume (EVLW/PBV) ratio. EVLWi (a) and EVLW/PBV (b) changes in the three experimental groups $(n=$ 6). White bars: time $0 \mathrm{~min}$; black bars: time $240 \mathrm{~min}$. The values are expressed as means \pm SD. a) ${ }^{*} p<0.05$ vs time 0 min in SB group; \# $p>0.05$ vs $\mathrm{V}_{\mathrm{T}} 8$ and $\mathrm{V}_{\mathrm{T}} 20$ groups at time $240 \mathrm{~min}$. b) ** $p<0.001$ vs time 0 min in $\mathrm{V}_{\mathrm{T}} 20$ group; \#\# $p<0.001$ vs $\mathrm{SB}$ and $\mathrm{V}_{\mathrm{T}} 8$ groups at time $240 \mathrm{~min}$.

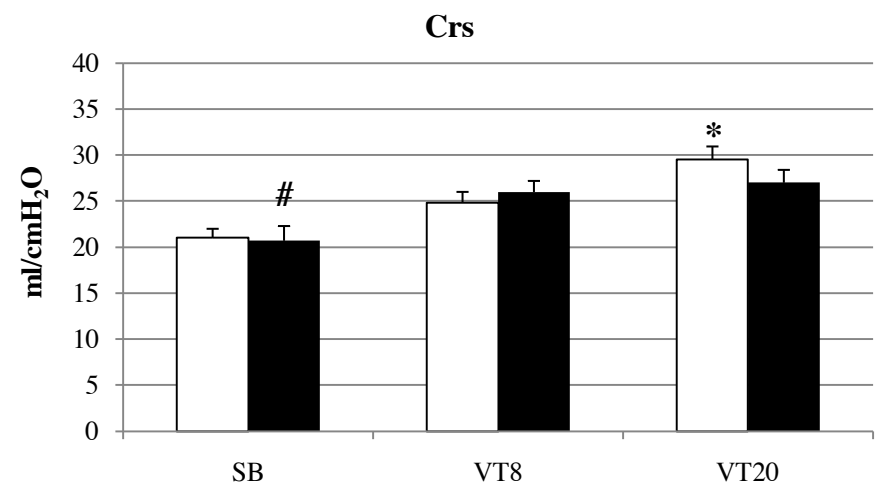

Figure 3. Respiratory system compliance (Crs). Crs changes in the three experimental groups $(n=6)$. White bars: time 0 min; black bars: time $240 \mathrm{~min}$. The values are expressed as means \pm SD. * $p<0.05$ vs SB and $\mathrm{V}_{\mathrm{T}} 20$ groups at time 0 min; $\# p<0.05$ vs $\mathrm{V}_{\mathrm{T}} 8$ and $\mathrm{V}_{\mathrm{T}} 20$ at time $240 \mathrm{~min}$. 
$\mathrm{PaO}_{2}$

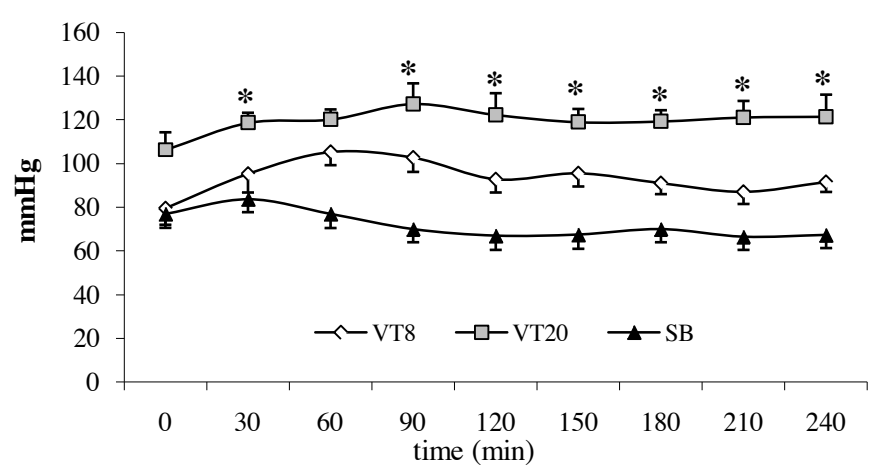

$\mathrm{PaCO}_{2}$

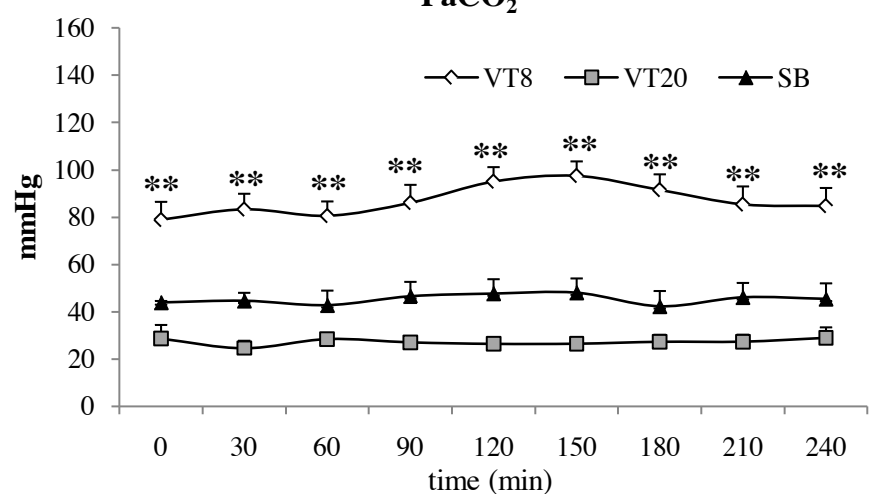

Figure 4. $\mathrm{PaO}_{2}$ and $\mathrm{PaCO}_{2}$. Time course of $\mathrm{PaO}_{2}$ (a) and $\mathrm{PaCO}_{2}$ (b) changes in all experimental groups $(n=6)$. The values are expressed as means $\pm \mathrm{SD}$. $\boldsymbol{a}){ }^{*} \mathrm{p}<0.05$ vs $\mathrm{SB}$ and $\mathrm{V}_{\mathrm{T}} 8$ groups. $\boldsymbol{b}$ ) $* *$ $\mathrm{P}<0.001$ vs $\mathrm{SB}$ and $\mathrm{V}_{\mathrm{T}} 20$ groups.

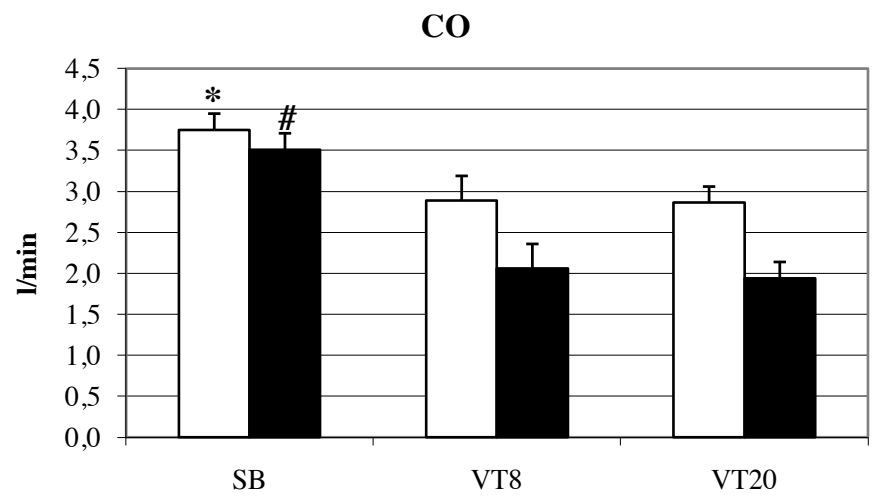

Figure 5. Cardiac output (CO). CO changes in the three experimental groups $(n=6)$. White bars: time 0 min; black bars: time $240 \mathrm{~min}$. The values are expressed as means \pm SD. ${ }^{*} \mathrm{p}<0.05$ vs $\mathrm{V}_{\mathrm{T}} 8$ and $\mathrm{V}_{\mathrm{T}} 20$ groups at time 0 min; \# $\mathrm{p}<0.05$ vs $\mathrm{V}_{\mathrm{T}} 8$ and $\mathrm{V}_{\mathrm{T}} 20$ groups at time $240 \mathrm{~min}$.

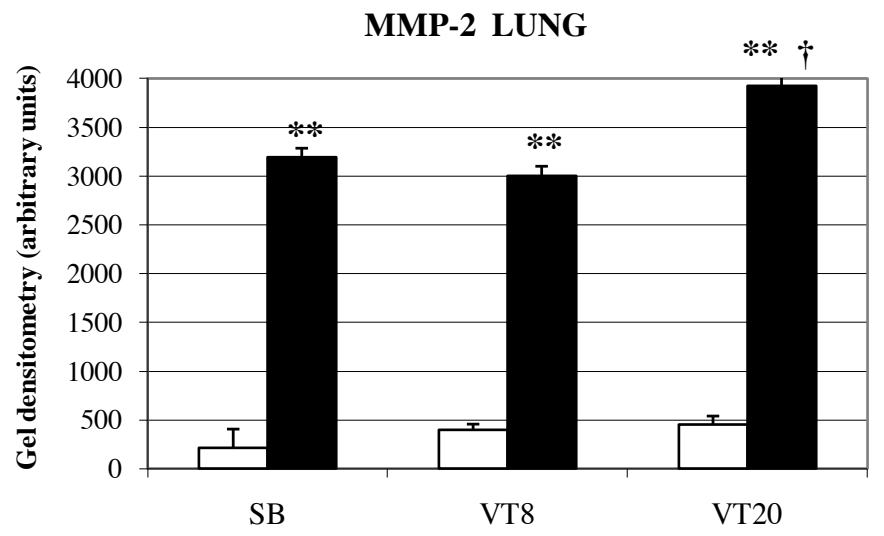

MMP-2 KIDNEY

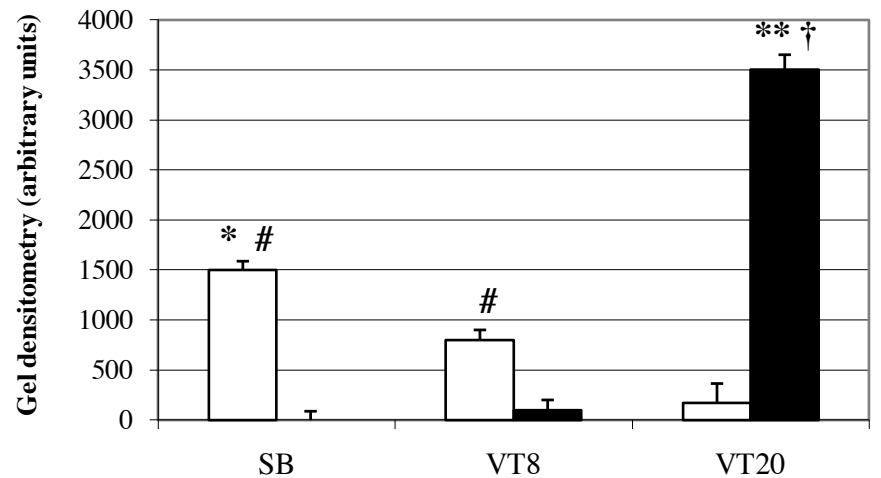

MMP-2 LIVER

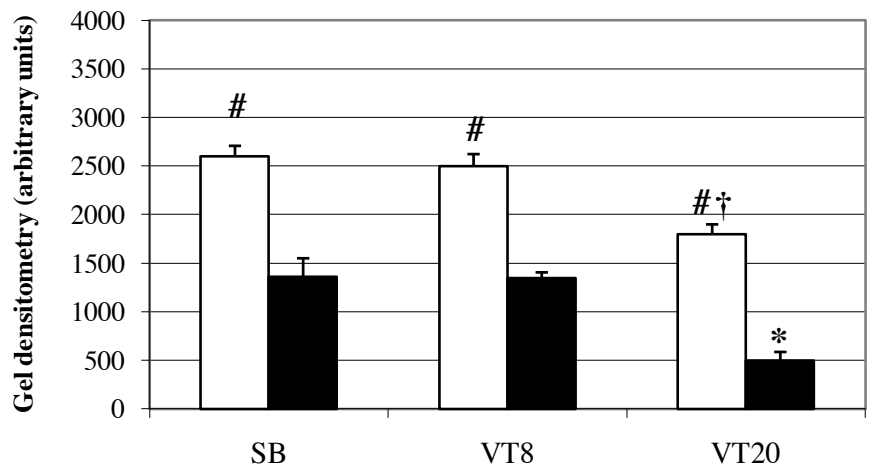

Figure 6. Pro and activated MMP-2 in lung, kidney and liver samples. MMP-2 changes in the lung $(\boldsymbol{a})$, in the kidney $(\boldsymbol{b})$ and in the liver (c) samples in the three experimental groups $(\mathrm{n}=$ 6). White bars: proMMP-2; black bars: activated MMP-2. a) $\dagger$ $p<0.05$ vs activated MMP-2 in SB and $\mathrm{V}_{\mathrm{T}} 8$ groups; ${ }^{*} p<0.001$ vs proMMP-2. b) $* p<0.05$ vs proMMP-2 in $\mathrm{V}_{\mathrm{T}} 8$ and $\mathrm{V}_{\mathrm{T}} 20$ groups; $* * p<0.001$ vs activated MMP-2 in SB and $\mathrm{V}_{\mathrm{T}} 8$ groups; $\dagger p<0.05$ vs proMMP-2; \# $p<0.05$ vs activated MMP-2. c) $† p<0.05$ vs proMMP-2 in SB and $\mathrm{V}_{\mathrm{T}} 8$ groups; ${ }^{*} p<0.05$ vs MMP-2 in SB and $\mathrm{V}_{\mathrm{T}} 8$ groups; $\# p<0.05$ vs activated MMP-2. 

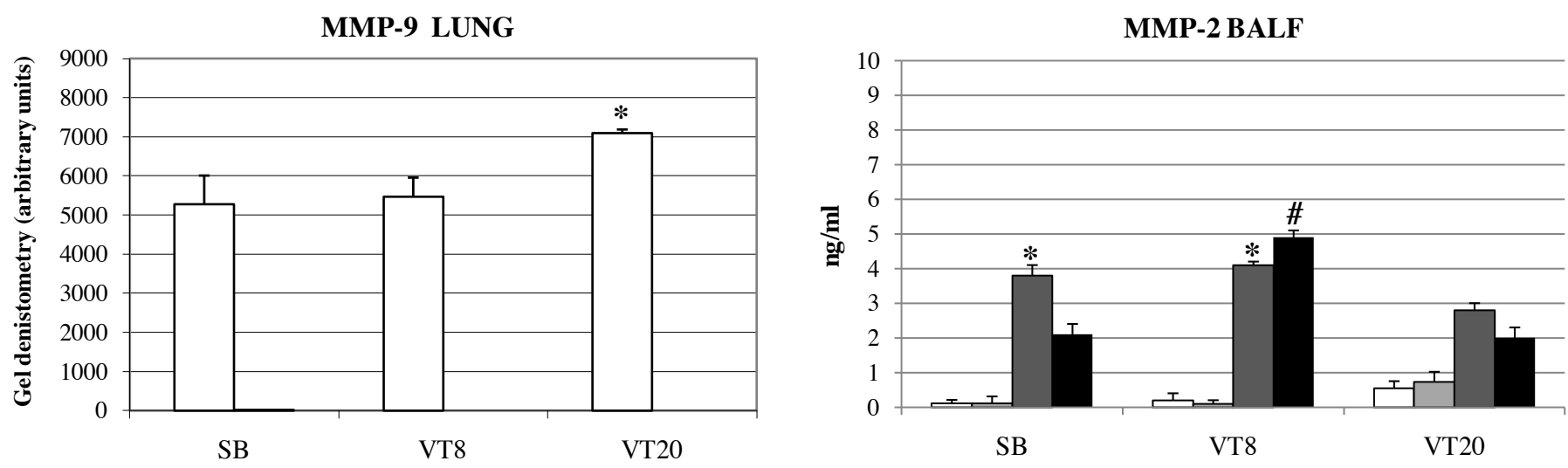

MMP-9 KIDNEY
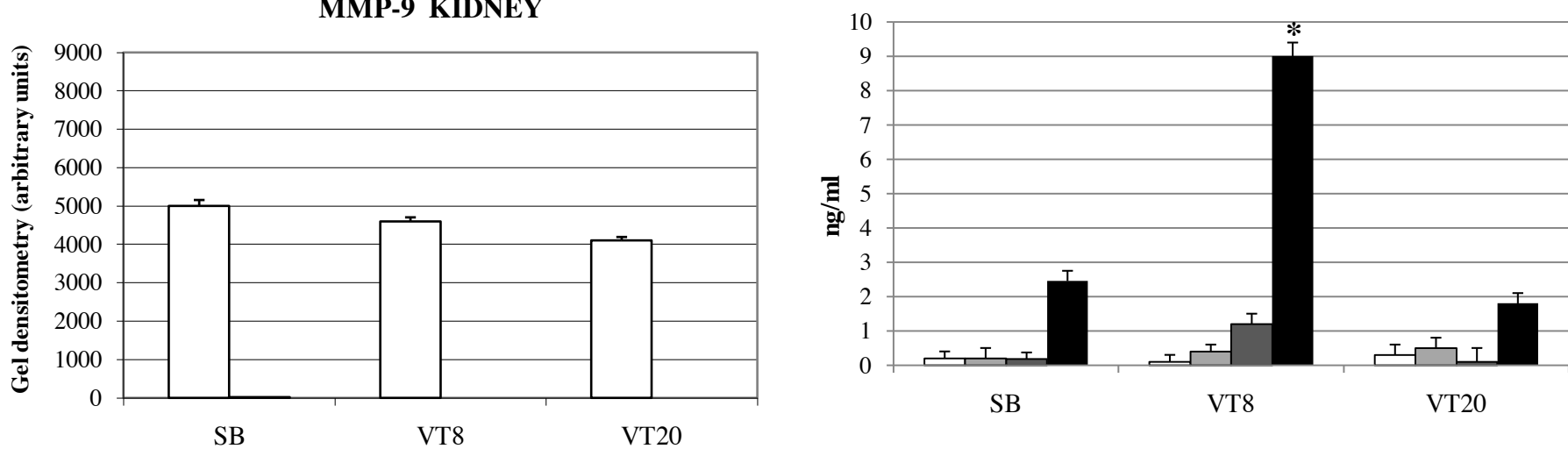

Figure 8. Pro and activated MMP-2 and pro and activated MMP9 in bronchoalveolar lavage fluid (BALF). MMP-2 (a) and MMP-9 (b) changes in BALF evaluated in all experimental groups $(\mathrm{n}=$ 6) at time $0 \mathrm{~min}$ and at time $240 \mathrm{~min}$. a) white bars: proMMP-2 time 0 min; grey bands: activated MMP-2 time 0 min; dark grey bands: proMMP-2 time $240 \mathrm{~min}$; black bars: activated MMP-2 time $240 \mathrm{~min}$. b) white bars: proMMP-9 time 0 min; grey bands: activated MMP-9 time 0 min; dark grey bands: proMMP-9 time $240 \mathrm{~min}$; black bars: activated MMP-9 time $240 \mathrm{~min}$. The values are expressed as means \pm SD. a) ${ }^{*} p<0.05$ vs proMMP-2 at time 0 min in SB and $V_{T} 20$ groups; \# $p<0.05$ vs activated MMP-2 in SB and $V_{T} 20$ groups at time $\left.240 \mathrm{~min} ; \boldsymbol{b}\right){ }^{*} p<0.05$ vs activated MMP-9 in $\mathrm{SB}$ and $\mathrm{V}_{\mathrm{T}} 20$ groups at time $240 \mathrm{~min}$.

TABLE I

Type and grading of lesions in histological lung samples in all experimental groups

Figure 7. Pro and activated MMP-9 in lung, kidney and liver samples. MMP-9 changes in the lung $(\boldsymbol{a})$, in the kidney $(\boldsymbol{b})$ and in the liver (c) samples in the three experimental groups $(n=$ 6). White bars: proMMP-9; activated MMP-9: not detectable. The values are expressed as means $\pm \mathrm{SD}$. a) ${ }^{*} p<0.05$ vs proMMP-9 in $\mathrm{SB}$ and $\mathrm{V}_{\mathrm{T}} 8$ groups.

\begin{tabular}{cccccc}
\multicolumn{7}{c}{ all experimental groups } \\
GROUP & AAE & IE & Atl & Brsp & Infl \\
\hline SB & 1 & 1 & 1 & 0 & 1 \\
$\mathbf{V}_{\mathrm{T}} \mathbf{8}$ & 1 & 1 & 1 & $\mathrm{~F}$ & 2 \\
$\mathbf{V}_{\mathrm{T}} \mathbf{2 0}$ & 4 & 1 & 2 & $\mathrm{~W}$ & 3 \\
\hline
\end{tabular}

AAE: acute alveolar emphysema; IE: interstitial emphysema; Atl: atelectasia; Brsp: bronchospasm; Infl: inflammation.

Score - 0: no lesions; 1: light and focal lesions; 2 : light and widespread lesions; $\mathbf{3}$ : moderate lesions; $\mathbf{4}$ : severe lesions; $\mathbf{F}$ : focal; $\mathbf{W}$ : widespread. 


\section{DISCUSSION}

The challenge of this study was to evaluate the onset of ventilator induced lung injury in a clinically relevant, validated and well-studied model, which closely resembles human physiology and the ventilator setting currently used in the clinical arena. Mechanical ventilation constitutes an indispensable tool for basic life support in the intensive care units and for major surgical procedures, and is undoubtedly essential for patients with acute lung injury/acute respiratory distress syndrome (ALI/ARDS). Despite the progress in medicine and biology, the underlying molecular mechanisms of ventilator induced lung injury (VILI) have not been fully elucidated, and the death rate of patients with ALI/ARDS remains quite high. Moreover, current studies on VILI are mainly based on rodent models that do not allow an accurate measurement of all the data regarding the changes in respiratory mechanics, in pulmonary arterial pressure and the evolution of gas exchanges and the permeability of alveolocapillary barrier. In recent years, it has become clear that mechanical ventilation can be injurious: repeated application of transalveolar pressures, that exceed those corresponding to the inflation capacity, causes tissue stresses leading to ventilator induced lung injury, with similar histological appearance to ALI/ARDS. These histological disorders are related to injury of the alveolar epithelium, basement membrane and microvascular endothelium and are characterized by highpermeability pulmonary edema (Nakos et al., 2006).

Our study demonstrates that both animals undergoing mechanical ventilation with high volumes and non-assisted breathing animals develop a massive lung edema, as revealed by extra-vascular lung water values. It is a daily dilemma for an intensivist to determine the mechanisms responsible for the EVLWi increase; in fact, this can be caused by an extravasation of fluid toward the interstitium, due to increased hydrostatic pressure into the pulmonary vascular bed, or by an increased permeability of the lung capillary membrane due to its damage, as during ALI or ARDS. Discriminating between these two mechanisms is an important issue, since the appropriate therapy differs (Hickling and Joyce, 1995). EVLWi is the only parameter assessable at the bedside, through which it is possible to evaluate the alveolo-capillary integrity, while the EVLW/PBV ratio is a rigorous index of permeability of pulmonary capillary district. Our results show that in the animals ventilated with high tidal volumes, the EVLW/PBV ratio reaches pathological levels, while in the SB group it remained almost unchanged. As expected, the alveolar overdistension induced cellular ultrastructural abnormalities only in animals subjected to high $\mathrm{V}_{\mathrm{T}}$ and not in those where lung distension was limited, as in our $\mathrm{V}_{\mathrm{T}} 8$ group, or absent, as in the SB group.

Our data show irrefutably that the severe edema formation noticed in spontaneously breathing animals was clearly related to the increase in pulmonary arterial pressure observed, which induced the extravasation of fluid into lung parenchyma. This may be related, at least in part, to breathing difficulties induced by the non-physiological supine position in which the animals were placed during the surgical and the experimental phases, and to the inhibitory effect on respiratory function induced by thiopental sodium used for anesthesia.

The compliance of the respiratory system typically decreases in correlation with the extravasation of fluid into lung parenchyma. In our data, unexpectedly, none of the groups of animals showed any statistically significant change during the experimental time. The Crs values were significantly different only when comparing time $0^{\prime}$ or time $240^{\prime}$ among groups. Pigs ventilated with high volume showed, at the beginning of the experimental time, an increase of Crs values, probably due to the compressing action exerted by the servoventilator, which, in the very first part of the experiment, has been shown to benefit also in terms of oxygenations, since $\mathrm{PaO}_{2}$ was significantly higher than in the other groups and $\mathrm{PaCO}_{2}$ significantly lower than in the $\mathrm{V}_{\mathrm{T}} 8$ group and close to that of SB animals. At the end of the experimental time, spontaneously breathing animals showed Crs values that were significantly lower than in the other two groups, reflecting the liquid extravasations induced by higher MPAP levels, confirming EWLVi data. Despite the increase of the pulmonary capillary district permeability, at $240^{\prime} \mathrm{V}_{\mathrm{T}} 20$ animals did not show any significant change compared to time $0 \mathrm{~min}$. This finding remains without a plausible explanation, especially considering that the histological analysis highlighted the worse lung injury status in the animals ventilated with high tidal volumes, that presented widespread and severe emphysema, inflammatory response, bronchoconstriction and atelectasia.

As expected, despite the alveolo-capillary injury, the oxygenation levels were significantly higher in the $\mathrm{V}_{\mathrm{T}} 20$ group. Oxygenation of the spontaneously breathing animals was impacted from the low tidal volumes and from the increase in MPAP, and thus resulted lower than the physiological range. It is well known that the organism is more sensitive to an increase of $\mathrm{PaCO}_{2}$ than to an increase of $\mathrm{PaO}_{2}$, indeed, in the SB group this condition was countered by an increase in pulmonary ventilation (data not reported) and, consequently, the values were into the physiological range. Contrarily, animals in the $\mathrm{V}_{\mathrm{T}} 8$ group, breathing with mechanical ventilation, could not modify respiratory frequency. Indeed, the ventilation strategy with $\mathrm{V}_{\mathrm{T}} 8$ leads to a moderate and not significant decrease of $\mathrm{PaO}_{2}$ concentration, while $\mathrm{PaCO}_{2}$ reached a severe and significant status of hypercapnia. However, hypercapnia is considered by some authors to play a protective role. Supporting this thesis, the inflammatory status developed in the $\mathrm{V}_{\mathrm{T}} 8$ group was moderate, as confirmed by histological analysis, probably through an attenuation of activation of nuclear factor-kappaB (NF-kB), a key regulator of the expression of multiple genes involved in the inflammatory response (Amato et al., 1998).

The protective effects of so called 'therapeutic hypercapnia' remain experimental at present, but promising laboratory studies suggest potential roles for eventual selective application at the bedside (Kavanagh and Laffey, 2006; Chonghaile et al., 2005). This 'permissive hypercapnia' is progressively catching on in critical care of adult, pediatric and neonatal patients requiring mechanical ventilation. Hickling and Joyce (1995) have demonstrated that hypercapnia improves cellular oxygen supply, but directly reduces the contractility of myocardium and vascular smooth muscle. Our results evidence that all animals presented a worsening of cardiac efficiency, and the impressive levels of $\mathrm{PaCO}_{2}$ achieved by $\mathrm{V}_{\mathrm{T}} 8$ group leads to a significant deterioration of cardiac function, confirming Hickling and Joyce findings. The stability in mean arterial blood pressure and heart rate, noted in all animals with no difference among the groups, was facilitated by fluid (normal saline) administration. 
Since ventilator induced lung injury is the result of a complex interplay among various mechanical forces acting on lung structures, including the extracellular matrix, we have also focused our attention on the gelatinases (Pelosi and Rocco, 2008). The expression of MMPs in the lung is a highly regulated process, and understanding its regulation could, in part, shed light into their biological function in physiological developmental processes and in many pathological conditions, including VILI (Greenlee et al., 2007).

In the lung sections examined, the proMMP-2 and his active form were expressed in all the animals, significantly in $\mathrm{V}_{\mathrm{T}} 20$ group, and the proportion between the two forms was largely in favor of the active one. Since MMP-2 is constitutively expressed, seems clear that the stretching stimulus by high $\mathrm{V}_{\mathrm{T}}$ was sufficient to induce its expression and activation, as already reported in literature (Haseneen et al., 2003; Greenlee et al., 2007).

All the lung samples presented high level of expression of the proMMP-9, which was significantly predominant in the $\mathrm{V}_{\mathrm{T}} 20$ group. None of the lung specimens revealed the presence of MMP-9 active form, underlining the fact that the stimulus was not suitable, or maybe not of sufficient duration, to its activation. On the contrary, the ELISA test on BAL fluid revealed the presence of MMP-9 active form, that surprisingly was extremely high in the $\mathrm{V}_{\mathrm{T}} 8$ group.

One of the possible mechanisms leading to the MMP-9 nonactivation in our lung tissue may be related to the mechanism of synthesis, release and activation of this gelatinase. The most important source of MMP-9 is represented by neutrophils and macrophages, which are recruited from the circulation. MMP9 is stored in latent form within gelatinases cellular granules, before being released into the extracellular space, following cell activation, and it needs, to attain full catalytic activity, a conformational change and auto-cleavage (Owen et al., 2003). At present, the in vivo physiological activator remains unclear, but in vitro studies indicated that other proteinases and reactive oxygen species can induce MMP-9 (Chow et al., 2007). The mechanism that underlies the over-expression in BALF of $\mathrm{V}_{\mathrm{T}} 8$ group remains unclear.

The same high values were evidenced by MMP-2 ELISA analysis: in BALF of $\mathrm{V}_{\mathrm{T}} 8$ animals, at time $240 \mathrm{~min}$, an impressive upregulation of activated MMP-2 was present, significantly higher than in BALF of the $\mathrm{SB}$ and $\mathrm{V}_{\mathrm{T}} 20$ groups. Unlike proMMP-9, the MMP-2 zymogen was expressed in all the animals at the end of the experimental time and reached significant higher values than time $0 \mathrm{~min}$ in the $\mathrm{SB}$ and $\mathrm{V}_{\mathrm{T}} 8$ groups. This finding may be related to the fact that MMP-2 is a constitutive gelatinase and, so, each type of stimulus is able to upregulate it; although, again, the rationale underlying the increased expression of activated MMP-2, and also of MMP-9, in the $\mathrm{V}_{\mathrm{T}} 8$ group remains unclear.

In order to characterize the systemic inflammatory response due to mechanical ventilation, we analyzed the gelatinases expression and activities in kidney and liver, since it has been described that most patients suffer from multisystem organ failure (ARDS network, 2000). In the kidney, the mechanical stress by high $\mathrm{V}_{\mathrm{T}}$ induced the almost complete activation of MMP-2, while, in the other two groups, the stimulus evoked the expression of the inactive form, but was not sufficient to determine its activation, except for a minimum part in $\mathrm{V}_{\mathrm{T}} 8$ animals. It is well known that mechanical ventilation may induce acute renal damage by three proposed mechanisms: through effects on arterial blood gases, through effects on systemic and renal blood flow and by triggering a pulmonary inflammatory reaction, with systemic release of vasoactive factors (Kuiper et al., 2005).

As with lung and liver tissues, the kidney MMP-9 was expressed only in pro-active form, underlining the fact that, once again, the stimulus was not suitable, or maybe not of sufficient duration, to its activation. Liver MMP-2 was expressed in all the animals as zymogen and as active form, even if, surprisingly, in animals treated with high $\mathrm{V}_{\mathrm{T}}$ the expression and the activation was significantly lower than in the other groups.

It is clear that mechanical ventilation strategies profoundly affects lung parenchyma integrity and functionality, and the choice of a ventilation strategy that avoids these damages, ensuring at the same time an appropriate exchange of gases, is firmly based on experimental literature and clinical experience. Thanks to the use of a model that closely resembles human physiology, we have observed the trend of the main parameters evaluated in intensive care units, parameters "lifesaving" for many patients who are forced to use mechanical ventilation. Although the use of low tidal volumes may reduce the onset of lung injury, in any case MV is harmful and further studies will be desirable in order to shed light on the mechanisms of VILI, to some extent still obscure. Further investigation will be necessary to better understand the underlying mechanisms of gelatinases synthesis, release and activation.

\section{ACKNOWLEDGMENTS}

This work was supported by MIUR (PRIN 2005) grant and FIRST 2006. The authors are grateful to Mr. Marco Costanzi for his valuable technical assistance.

\section{REFERENCES}

ALBAICETA GM, GUTIÉRREZ-FERNÁNDEZ A, PARRA D, ASTUDILLO A, GARCÍA-PRIETO E, TABOADA F, FUEYO A (2008) Lack of matrix metalloproteinase- 9 worsens ventilator-induced lung injury. Am J Physiol Lung Cell Mol Physiol 294: L535-43.

AMATO MB, BARBAS CS, MEDEIROS DM et al. (1998) Effect of a protective-ventilation strategy on mortality in acute respiratory distress syndrome. N Eng J Med 338: 195-199.

ARDS - THE ACUTE RESPIRATORY DISTRESS SYNDROME - NETWORK (2000) Ventilation with lower tidal volumes as compared with traditional tidal volumes for acute lung injury and the acute respiratory distress syndrome. N Engl J Med 342: 1301-1308.

CLEMENT MG, MARZANI M, DIMORI M, ALBERTINI M (1998) Prostanids counterbalance the bronchoconstrictor activity of endothelin-1 in pigs. Prost Leuk and Ess Fatty Acids 58:177-183.

ChONGHAile M, HIGGins B, LAfFeY JG (2005) Permissive hypercapnia: role in protecting lung ventilator strategies. Curr Opin Crit Care 11:56-62.

CHOW AK, CENA J, SCHULZ R (2007) Acute actions and novel targets of matrix metalloproteinases in the heart and vasculature. Br J Pharmacol 152: 189-205.

DREYFUSS D, SAUMON G (1998) Ventilator-induced lung injury: lessons from experimental studies. Am J Respir Crit Care Med 157: 294-323.

DREYFUSS D, BASSET G, SOLER P, SAUMON G (1985) Intermittent positive-pressure hyperventilation with high inflation pressures produces pulmonary microvascular injury in rats. Am Rev Respir Dis 132:880-884

GREENLEE KJ,WERB Z, KHERADMAND F (2007) Matrix metalloproteinases in lung: multiple, multifarious and multifaceted. Physiol Rev 87: 69-98.

HASENEEN NA, VADAY GG, ZUCKER S, FODA HD (2003) Mechanical stretch induces MMP-2 release and activation in lung endothelium: role of EMMPRIN. Am J Physiol Lung Cell Mol Physiol 284: L541-L547. 
HICKLING KG, JOYCE C (1995) Permissive hypercapnia in ARDS and its effects on tissue oxygenation. Acta Anaesthesiol Scand 107: 201-208.

KAVANAGH KG, LAFFEY JG (2006) Hypercapnia: permissive and therapeutic. Minerva Anaestesiol 72: 201-208.

KUIPER JW, GROENEVELD ABJ, SLUTSKY AS, PLOTZ FB (2005) Mechanical ventilation and acute renal failure. Crit Care Med 33: 1408-1415.

NAKOS G, BATISTATOU A, GALIATSOU E, KOSTANTI E, KOULOURAS $\mathrm{V}$, KANAVAROS $\mathrm{P}$, DOULIS A, KITSAKOS A, KARACHALIOU A, LEKKA M, BAI M (2006) Lung and 'end organ' injury due to mechanical ventilation in animals: comparison between the prone and supine position. Crit Care 10: R38.

OWEN CA, HU Z, BARRICK B, SHAPIRO SD (2003) Inducible expression of tissue inhibitor of metalloproteinases-resistant matrix metalloproteinase- 9 on the cell surface of neutrophils. Am J Respir Cell Mol Biol 29: 283-294.

PELOSI P, ROCCO PR (2008) Effects of mechanical ventilation on the extracellular matrix. Intensive Care Med 34:631-639.

PINGLETON SK (1988) Complications of acute respiratory failure. Am Rev Resp Dis 137: 1463-1493.
RICARD JD, DREYFUSS D, SAUMON G (2003) Ventilator-induced lung injury. Eur Resp J 22: 2s-9s.

TOMASHEFSKI JF JR (1990) Pulmonary pathology of the adult respiratory distress syndrome. Clin Chest Med 11: 593-619.

VANEKER M, HALBERTSMA FJ, VANEGMOND J, NETEA MG, DIJKMAN HB, SNIJDELAAR DG, JOOSTEN LA, VANDERHOEVEN JG, SCHEFFER GJ (2007) Mechanical ventilation in healthy mice induces reversible pulmonary and systemic cytokine elevation with preserved alveolar integrity. Anesthesiology 107: 419-426.

VIGETTI D, MORETTO P, VIOLA M, GENASETTI A, RIZZI M, KAROUSOU E, PALLOTTI F, DE LUCA G, PASSI A (2006) Matrix metalloproteinase 2 and tissue inhibitors of metalloproteinases regulate human aortic smooth muscle cell migration during in vitro aging. Faseb J 20: 1118-1130.

WIRTZ HR, DOBBS LG (2000) The effects of mechanical forces on lung functions. Respir.Physiol 119:1-7

WOESSNER JF JR (1991) Matrix metalloproteinases and their inhibitor in connective tissue remodelling FASEB J 5: 2145-2154. 
